\title{
Evaluation of Kostiakov's and Philip's infiltration models on the soil of Dediapada, India
}

\section{A. H. Jagani}

College of Agricultural Engineering and Technology, Navsari Agricultural University, Dediapada (Gujarat), India

\section{P. K. Shrivastava}

College of Forestry, ACHF, Navsari Agricultural University, Navsari (Gujarat), India

D. K. Dwivedi*

College of Forestry, ACHF, Navsari Agricultural University, Navsari (Gujarat), India

*Corresponding author. E-mail : dhavaldwivedi42@gmail.com

\begin{abstract}
Infiltration models are used in designing and optimizing irrigation projects as they are capable of predicting infiltration rate and accumulated infiltration depth to a reasonable level of accuracy. The objective of this study deals with obtaining the parameters of infiltration models like Kostiakov and Philip, applying these models to the soil of Dediapada and evaluating their performance by comparing it with the observed infiltration. Firstly, the accumulated infiltration and infiltration rates were determined by the field measurement using a double ring infiltrometer. Kostiakov's and Philip's infiltration models were then applied to obtain simulated data once its parameters were ascertained. The estimated parameters ' $m$ ' and ' $n$ ' for the Kostiakov model were 0.1311 and -0.3092 respectively and the corresponding equations obtained for estimating infiltration rate and accumulated infiltration depth were $0.13 \mathrm{t}^{-0.30}$ and $0.19 \mathrm{t}^{0.69}$. The estimated parameters ' $s$ ' and ' $k$ ' for the Philip model were 0.32 and 0.014 respectively and the corresponding equations obtained for estimating infiltration rate and accumulated infiltration depth were $0.16 \mathrm{t}^{-0.5}+0.014$ and $0.32 \mathrm{t}^{0.5}+0.014 \mathrm{t}$. The coefficient of determination values for evaluating the performance of the model were obtained in excess of 0.95 for both the models. Due to lack of research on the application of infiltration models on the clay loam soil of Dediapada, this study would prove to be useful for estimation of infiltration rate and depth.
\end{abstract}

Keywords: Infiltration rate, Infiltration Depth, Kostiakov model, Model parameter, Philip model.

\section{INTRODUCTION}

The entry of water from irrigation or rainfall into a soil is termed as infiltration. The rate at which the infiltration occurs through the soil is called infiltration rate and it is governed by the condition of the soil surface, soil texture, soil structure, antecedent moisture conditions and vegetative cover. Infiltration plays an important role in optimizing the irrigation projects as well as in estimating the groundwater recharge, runoff and chemical transport through subsurface water (Igbadun and Idris, 2007). Thus, infiltration is of paramount importance in management of soil and water resources and it is also an imperative variable in

\section{Article Info}

DOI:10.31018/jans.v10i3.1845

Received: July 30, 2018

Revised: August 23, 2018

Accepted: August 30, 2018

\section{How to Cite}

Jagani, A. et al. (2018).

Evaluation of Kostiakov's

and Philip's infiltration models on the soil of Dediapada, India. Journal of Applied and Natural Science, 10(3): 1073-1077 
surface and groundwater bodies. Only 18 to $20 \%$ of the water is actually used due to lack of adequate infrastructure and inappropriate water management (Dhawan, 2017). India's annual rainfall is around $1183 \mathrm{~mm}$, out of which $75 \%$ is received in a short span of four months during monsoon (July to September). Dedipada located in Narmada district of Gujarat state in India receives an average annual rainfall of $1139 \mathrm{~mm}$, out of which $1109 \mathrm{~mm}$ of rainfall occurs in monsoon season (Lakkad and Shrivastava, 2016).

Infiltration modes are useful for estimating the water infiltrated into the soil as the amount of water stored in the root zone should be ascertained to design irrigation systems. Infiltration models are classified into three categories: physical models, semi-empirical models and empirical models (Philip, 1957). The data observed in field can be used for deriving empirical models. Kostiakov and Philip models are empirical model whose parameters can be determined from observed infiltration rate. The detailed procedure of estimating parameters has been given in 'Materials and Methods' section. The steady infiltration rate process after a sufficiently large time is described by Kostiakov model which shows a decreasing infiltration rate as a function of time. The infiltration rate tends to zero for high opportunity time in case of Kositakov's model. This is one of the shortcomings of Kostiakov's model as infiltration rate can never be zero.

Ruth et al. (2014) applied Kostiakov's infiltration model on the soil of Umudike, Nigeria and found that there was a close relationship between the simulated and observed infiltration data. The coefficients obtained for " $m$ " were: 0.53 for P.G. block, 0.41 for the soils of Staff School and Guest House. The corresponding " $n$ " values ranged from 0.37 - 1.79. Infiltration equations obtained for the soil were $0.41 \mathrm{t}^{1.38}, 0.41 \mathrm{t}^{1.79}, 0.50 \mathrm{t}^{0.37} 0.42 \mathrm{t}^{1.12}$ and $0.53 \mathrm{t}^{1.37}$ Zakwan et al. (2016) utilized the field infiltration data of sandy loam soils of IkwuanoUmuahia located in south-eastern Nigeria to assess the performance of prediction models like Kostiakov, Horton and Philip. They concluded that the performance of Kostiakov model was better than the Horton's model and Philip's model with correlation coefficient value of 0.99 . Singh et al. (2018) measured the infiltration rate in NIT Kurukshetra using double ring infiltrometer evaluated the performance of infiltration models like Horton and Philip. They concluded that Philip's model was the most accurate model with correlation coefficient value of 0.99 and this model can be used to simulate the infiltration data under similar conditions.

Based on the importance of the infiltration rate and accumulated infiltration in soil and water management, the study has been taken to determine the parameters of infiltration models like Kostiakov and Philip, applying these models to the soil of Dediapada and evaluating their performance by comparing it with the observed infiltration.

\section{MATERIALS AND METHODS}

Dediapada taluka is situated in Narmada district of South Gujarat at $21^{\circ} 66^{\prime}$ N latitude and $73^{\circ} 59^{\prime}$ Iongitude with an elevation of $169 \mathrm{~m}$ above mean sea level. The infiltration data were obtained from the field located in campus of College of Agricultural Engineering and Technology, Dediapada. The texture of the soil was clay loam. Double ring infiltrometers were used to determine the infiltration rates $(\mathrm{cm} / \mathrm{min})$ and accumulated depth of infiltration $(\mathrm{cm})$. The inner cylinder was $30 \mathrm{~cm}$ in diameter and the outer cylinder which was used to form buffer pond was $60 \mathrm{~cm}$ in diameter. The cylinders were installed about $10 \mathrm{~cm}$ deep in soil. The cylinders were driven into the ground by a falling weight type hammer striking a wooden plank placed on top of the cylinders. The point rod was set at a desired level to which water was added. Water was added to the inner cylinder from a container of known volume and a graduated jar. A stop watch was used to note the instant the addition of water began and the time the water reached the desired level. The difference between the quantity of water added and the volume of water in the cylinder at the instant it reached the desired point was taken as the quantity of water that infiltrated during the time interval between start of filling and first measurement. After the initial reading, point gauge measurements were made at frequent intervals of $5,10,15$ and 30 minutes to determine the amount of water that has infiltrated during the time interval.

A brief description of Kostiakov's and Philip's model used in this study is given below:

Kostiakov's infiltration model: Kostiakov (1932) proposed an equation to calculate infiltration rate and accumulated infiltration depth.

$$
\begin{aligned}
& f=k t^{-n} \\
& d=\frac{k}{-n+1} t^{-n+1}
\end{aligned}
$$

where, $f=$ infiltration rate $(L / T), t=$ time elapsed since the beginning of infiltration $(T), k$ and $n=$ empirical constants which are site specific and depend on soil properties

The Kostiakov equation indicates that the infiltration rate will approach zero after a long period of time which is physically not correct. However, this equation adequately represents infiltration over a limited time which is generally satisfactory in irrigation practices.

To obtain the parameters of Kostiakov equation, log is taken both sides of equation (1),

$$
\log f=\log k+(-n) \log t
$$

A plot of 'log $f$ vs log t' gives a straight line whose 
slope gives the value of ' $n$ ' while the intercept gives the value of 'log k'.

The value of ' $k$ ' is obtained by taking antilog $k$ i.e. $k=10^{\log k}$

Philip's infiltration model: Philip (1957) derived the following equation of infiltration rate.

$d=S t^{1 / 2}+A t$

where, $d=$ cumulative infiltration $(L), A=$ constant, $\mathrm{S}=$ Sorptivity $\left(\mathrm{L} / \mathrm{T}^{0.5}\right)$, Differentiating equation (5) gives an expression for infiltration rate of the soil. $f=\frac{5}{2} t^{-1 / 2}+A$

Where, $f$ is the infiltration rate $(L / T)$

At small times, the first term is significant indicating that capillary forces predominate and at large times, the second term is significant indicating that gravity forces predominate.

On an arithmetic graph, infiltration rate is plotted against inverse square root of time to obtain the parameters of the Philip's equation. A best fit straight line is obtained whose slope represents the value of $K$ and the intercept gives the value of $\mathrm{S} / 2$.

Performance evaluation: Coefficient of determination provides a measure of how well the observed values are replicated by the model, based on the proportion of total variation of outcomes explained by the model. It is represented by $R^{2}$.

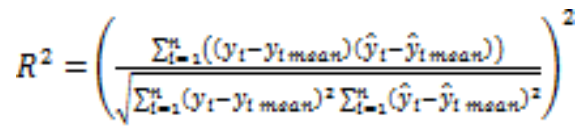

\section{RESULTS}

The infiltration rate $(\mathrm{cm} / \mathrm{min})$ and the accumulated infiltration $(\mathrm{cm})$ were plotted with respect to time as shown in Fig. 1 and Fig. 2 respectively. The predicted infiltration rate by Kostiakov's and Philip's model was compared with the observed values as shown in Fig. 3 and Fig. 4. The predicted cumulative infiltration by Kostiakov's and Philip's model was compared with the observed values as shown in Fig. 5 and Fig. 6. The infiltration equation and its parameters are given in Table 1 and the performance of both the models in terms of coefficient of determination is given in

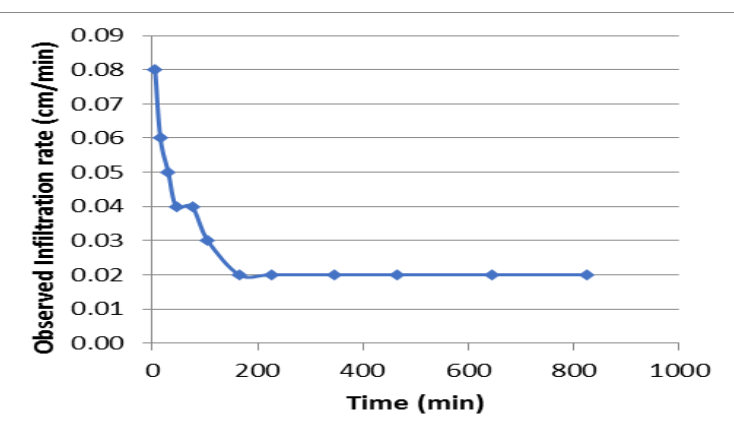

Fig. 1. Observed infiltration rate vs. time.

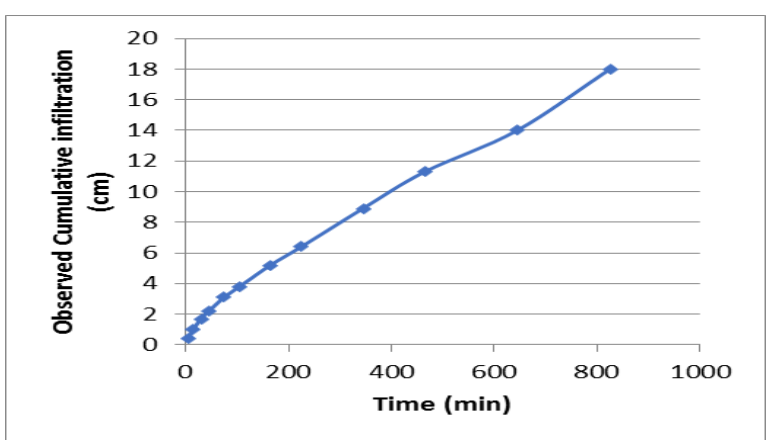

Fig. 2. Observed cumulative infiltration vs. time.

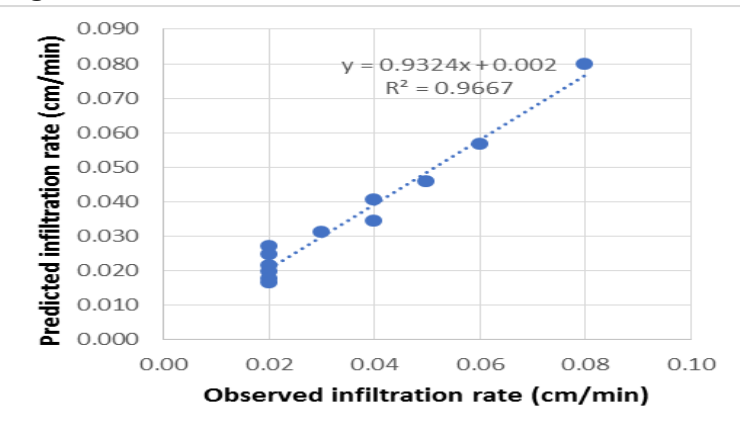

Fig. 3. Observed vs. Predicted infiltration rate (Kostiakov).

Table 2.

The parameter ' $\mathrm{t}$ ' in the equations shown in Table 1 is the time elapsed while y' and ' $d$ ' represent the infiltration rate and cumulative infiltration respectively. The constant ' $n$ ' in the Kostiakov equation is preceded by a negative sign indicating that the infiltration rate decreases with time. The constants 'S'and ' $A$ ' of the Philip equation given in Table 1

Table 1. Infiltration equation with its parameters.

\begin{tabular}{|c|c|c|c|}
\hline \multicolumn{4}{|c|}{ Kostiakov } \\
\hline Infiltration rate (cm/min) & Cumulative infiltration (cm) & $\mathbf{k}$ & $\mathbf{n}$ \\
\hline$y=0.1311 t^{-0.3092}$ & $\mathrm{~d}=0.1898 \mathrm{t}^{0.6908}$ & 0.13116 & 0.3092 \\
\hline \multicolumn{4}{|c|}{ Philip } \\
\hline Infiltration rate (cm/min) & Cumulative infiltration (cm) & $\mathbf{S}\left(\mathrm{cm} / \mathrm{min}^{0.5}\right)$ & $\mathbf{A}$ \\
\hline$y=0.1603 t^{-0.5}+0.014$ & $\mathrm{~d}=0.3206 \mathrm{t}^{0.5}+0.014 \mathrm{t}$ & 0.3206 & 0.014 \\
\hline
\end{tabular}

Table 2. Performance of the model in terms of root mean square error and coefficient of determination values

\begin{tabular}{llll}
\hline Infiltration rate & & Cumulative infiltration & \\
\hline $\mathbf{R}^{2}$ (Kostiakov) & $\mathbf{R}^{2}$ (Philip) & $\mathbf{R}^{2}$ (Kostiakov) & $\mathbf{R}^{2}$ (Philip) \\
\hline 0.9667 & 0.9456 & 0.9958 & 0.9986 \\
\hline \hline
\end{tabular}




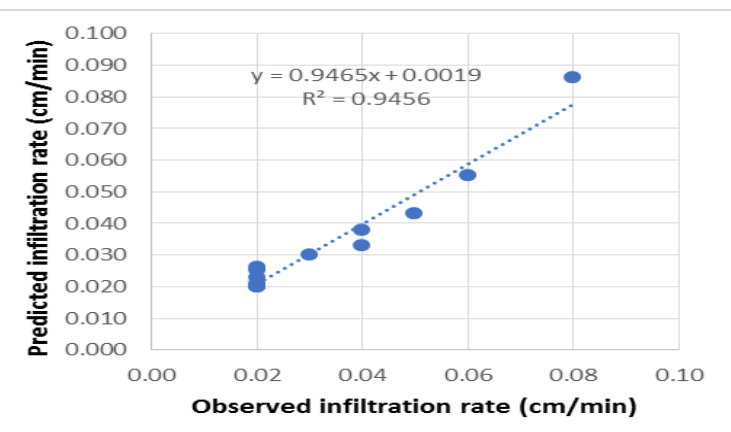

Fig. 4. Observed vs. Predicted infiltration rate (Philip).

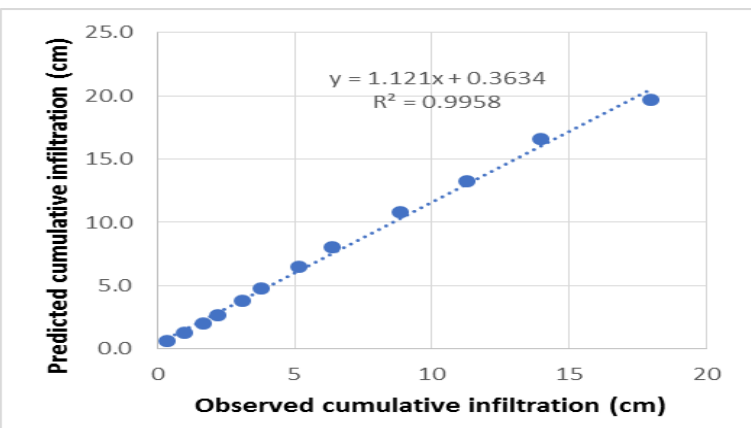

Fig. 5. Observed vs. Predicted cum. infiltration (Kostiakov).

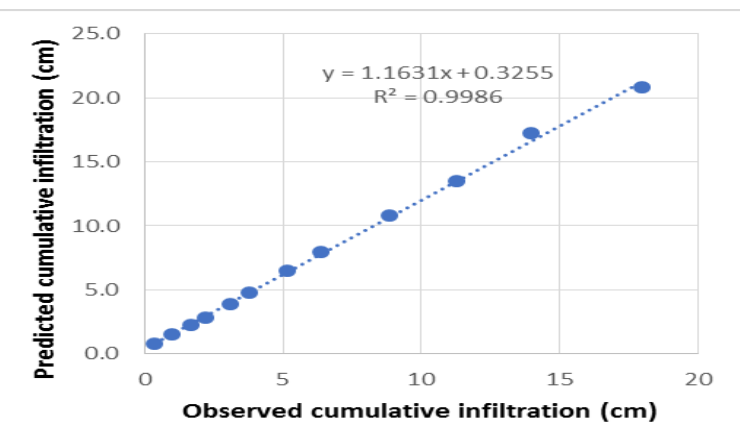

Fig. 6. Observed vs. Predicted cum. infiltration (Philip).

indicate the domination of the capillary forces and gravity forces respectively. .It could be observed from the comparison graph of observed and predicted infiltration rates (Fig. 3) that the simulated data of Kostiakov model closely followed the observed data which is indicated by its high coefficient of determination value of 0.96 which means that there was close agreement between the observed and simulated data while in case of simulated data (Fig. 4) of Philip model was also found to be in proximity with the observed data but its coefficient of determination value of 0.94 was less compared to that of Kostiakov model. Thus, it can be concluded that the Kostiakov model performed better than Philip model, however, either of the model can be successfully used for simulating data as their coefficient of determination values were high while from the comparison graph of observed and predicted cumulative infiltration
(Fig. 5 and Fig. 6) it is seen that the simulated data of Kostiakov model and Philip model closely followed the observed data which is indicated by its high coefficient of determination value of 0.99 Thus, both models performed exceptionally well in simulating cumulative infiltration data. $y=0.1311 \mathrm{t}^{-}$ 0.3092 and $\mathrm{d}=0.1898 \mathrm{t}^{0.6908}$ are the Kostiakov equations for infiltration rate and cumulative infiltration respectively. The equations of Philip are $\mathrm{y}=0.1603 \mathrm{t}^{-0.5}+0.014$ and $\mathrm{d}=0.3206 \mathrm{t}^{0.5}+0.014 \mathrm{t}$ for infiltration rate and cumulative infiltration respectively. Sorptivity obtained by Philip's equation was $0.32 \mathrm{~cm} / \mathrm{min}^{0.5}$

\section{DISCUSSION}

It was observed that the simulated data obtained by applying the Kostiakov model and Philip model were found to be in close agreement with the observed infiltration data as proved by the coefficient of determination values of 0.96 and 0.94 . As the coefficient of determination is in excess of 0.90 for both the models, it could be inferred that Kostiakov model should be utilized for simulating infiltration rate. As the coefficient of determination is close to 1 in case of both the models for cumulative infiltration, it can be said that either of the two models could be utilized in simulating cumulative infiltration data. The parameters of the models obtained could be effectively used for estimating the amount of storage in the soil during rainfall from which an approximation of the runoff and other losses could be made. Uloma et al. (2014) also employed a similar procedure to estimate infiltration parameters and they also obtained a coefficient of determination above 0.90 for Kostiakov model. Haghiabi et al. (2011) used logarithmic characteristic of infiltration data similar to this study and their results showed that the Kostiakov equations could estimate with high precision using the proposed method. Equations given in Table 1 can be used for accurately predicting infiltration rate and cumulative infiltration for similar conditions. Irrigation project can be planned and optimized based on the simulated data before its implementation. The constants of the equation are based on soil conditions and they are strictly site specific, however, they could also be used on other sites for obtaining an approximation pertaining to infiltration data. Several other infiltration models could also be used; however, Kostiakov and Philip model are used due to their simplicity and reliability.

\section{Conclusion}

The objective of this study was to determine the parameters of infiltration models like Kostiakov and Philip, applying these models to the soil of Dediapada and evaluating their performance by comparing it with the observed infiltration. Kostiakov's and Philip's infiltration models were applied 
to obtain simulated data once its parameters were ascertained. The estimated parameters ' $m$ ' and ' $n$ ' for the Kostiakov model were 0.1311 and -0.3092 respectively and the corresponding equations obtained for estimating infiltration rate and accumulated infiltration depth were $0.13 \mathrm{t}^{-0.30}$ and $0.19 \mathrm{t}^{0.69}$. The estimated parameters ' $\mathrm{s}$ ' and ' $\mathrm{k}$ ' for the Philip model were 0.32 and 0.014 respectively and the corresponding equations obtained for estimating infiltration rate and accumulated infiltration depth were $0.16 t^{-0.5}+0.014$ and $0.32 t^{0.5}+0.014 t$. The coefficient of determination value when compared with the observed infiltration rate was found to be 0.96 (Kostiakov) and 0.94 (Philip). Therefore, these models could successfully be used for simulating infiltration data needed in planning irrigation projects and also required for management of soil and water resources.

\section{REFERENCES}

1. Haghiabi, A. H., Abedi-Koupai, J., Heidarpour, M., \& Mohammadzadeh-Habili, J. (2011). A new method for estimating the parameters of Kostiakov and modified Kostiakov infiltration equations. World Applied Sciences Journal, 15(1): 129-135.

2. Igbadun, H.E. and Idris, U.D. (2007). Performance Evaluation of infiltration Model in a Hydrmorphic oil. Nig. Jour. \& Env. Res., 7:53-59. https://doi:10.5923/ j.ajee.20140401.01
3. Kostiakov, A. N. (1932). The dynamics of the coefficients of water percolation in soils and the necessity for studying it from a dynamic point of view for purpose of amelioration. Society of Soil Sci.,14: 17-21.

4. Lakkad, A. P., and Shrivastava, P. K. (2016). Crop planning through rainfall analysis for dediapada region of south Gujarat agro-climatic zone. Research in Environment and Life Sciences, 9: 350-355.

5. Mudiare, O.J. and Adewunmi, J.K. (2000). Estimation of infiltration from field-measured sorptivity values. Nigerian Journal of soil science Research, 1:1-3.

6. Philip, J. (1957). Theory of infiltration: The infiltration equation and its solution. Soil Science, 83(5): 345357.

7. Ruth. U., Kelechi K., Timothy, O., and Ike-Amadi C. (2014). Application of Kostiakov's Infiltration Model on the Soils of Umudike, Abia State, Nigeria. American Journal of Environmental Engineering, 4(1): 1-6 https://doi:10.5923/j.ajee.20140401.01

8. Singh, B., Sihag, P. And Singh, K. (2018). Comparison of infiltration models in NIT Kurukshetra campus. Applied Water Science, 8(1):63 https:// doi.org/10.1007/s13201-018-0708-8

9. Uloma, A. R., Samuel, A. C., \& Kingsley, I. K. (2014). Estimation of Kostiakov's infiltration model parameters of some sandy loam soils of Ikwuano-Umuahia, Nigeria. Open Trans. Geo. Sci., 1(1): 34-38.

10.Zakwan, M., Muzzammil, M. and Alam, J. (2016). Application of spreadsheet to estimate infiltration parameters. Perspectives in Science, 8(1): 702-704 https://doi.org/10.1016/j.pisc.2016.06.064 